\title{
Analysis of the acute response of Galleria mellonella larvae to potassium nitrate
}

\author{
Ronan Maguire ${ }^{\mathrm{a}}$, Martin Kunc ${ }^{\mathrm{b}}$, Pavel Hyrsl ${ }^{\mathrm{b}}$, Kevin Kavanagh ${ }^{\mathrm{a}, *}$ \\ a Department of Biology, Maynooth University, Co. Kildare, Ireland \\ ${ }^{\mathrm{b}}$ Department of Animal Physiology and Immunology, Institute of Experimental Biology, Faculty of Science, Masaryk University, Kotlarska 2, 611 37 Brno, Czech Republic
}

\section{A R T I C L E I N F O}

\section{Article history:}

Received 13 December 2016

Received in revised form 3 February 2017

Accepted 14 February 2017

Available online 20 February 2017

\section{Keywords:}

Galleria mellonella

In vivo

Potassium nitrate

Toxicity

\begin{abstract}
A B S T R A C T
Potassium nitrate (E252) is widely used as a food preservative and has applications in the treatment of high blood pressure however high doses are carcinogenic. Larvae of Galleria mellonella were administered potassium nitrate to establish whether the acute effects in larvae correlated with those evident in mammals. Intra-haemocoel injection of potassium nitrate resulted in a significant increase in the density of circulating haemocytes and a small change in the relative proportions of haemocytes but haemocytes showed a reduced fungicidal ability. Potassium nitrate administration resulted in increased superoxide dismutase activity and in the abundance of a range of proteins associated with mitochondrial function (e.g. mitochondrial aldehyde dehydrogenase, putative mitochondrial Mn superoxide dismutase), metabolism (e.g. triosephosphate isomerase, glyceraldehyde 3 phosphate dehydrogenase) and nitrate metabolism (e.g. aliphatic nitrilase, glutathione $S$-transferase). A strong correlation exists between the toxicity of a range of food preservatives when tested in G. mellonella larvae and rats. In this work a correlation between the effect of potassium nitrate in larvae and mammals is shown and opens the way to the utilization of insects for studying the in vivo acute and chronic toxicity of xenobiotics.
\end{abstract}

(ㄷ) 2017 Elsevier Inc. All rights reserved.

\section{Introduction}

The immune system of insects bears structural and functional similarities to the innate immune response of mammals (Browne et al., 2013) and this offers the possibility of utilizing insects as in vivo models without any of the legal or ethical issues that surround the use of mammals (Kavanagh and Reeves, 2004). Insects are now widely used to study the virulence of microbial pathogens (Fuchs and Mylonakis, 2006; Cotter et al., 2000) and to assess the in vivo antimicrobial activity of compounds (Browne et al., 2014; Debois and Coote, 2012) and often generate results that show a strong correlation to those obtained using mammals (Jander et al., 2000; Brennan et al., 2002). Larvae of the Greater wax moth (Galleria mellonella) offer the advantage of being inexpensive to purchase and house, easy to inoculate, and statistically robust data can be generated quickly (Cook and McArthur, 2013). Larvae can be administered compounds by force feeding or by intra-haemocoel injection and their response can be monitored by assessing changes in the density of circulating immune cells (haemocytes) (Bergin et al., 2003), alterations in protein and/or gene expression (Fallon et al., 2012), the

Abbreviations: BP, biological processes; EST, Expression Sequence Tag; FDR, False Discovery Rates; GDN, glyceryl dinitrate; GO, gene ontology terms; GTN, nitroglycerin; LD, lethal dose; MP, molecular function; MS, mass spec; PBS, Phosphate Buffer Saline; ROS, reactive oxygen species; FACs, Fluorescence-activated cell sorting.

* Corresponding author at: Department of Biology, Maynooth University, Co. Kildare, Ireland.

E-mail address: kevin.kavanagh@nuim.ie (K. Kavanagh). appearance of melanisation or by mortality (Tsai et al., 2016). The use of G. mellonella larvae has recently been extended to study Listeria-induced neural pathologies (Mukherjee et al., 2010) and also to assess the relative toxicity of novel antimicrobial agents (Aneja et al., 2016) and food preservatives (Maguire et al., 2016).

A wide range of insect species have been employed for measuring the acute and chronic toxicity of pesticides (Buyukguzel et al., 2013), solvents (Soos and Szabad, 2014) and nanoparticles (Carmona et al., 2015). Tribolium castaneum has been utilized to analyse the effect of acrylamide (Grunwald et al., 2014) and demonstrated a positive correlation with results obtained using rats (Wang et al., 2010). The Drosophila wing spot test has been employed for measuring the genotoxicity of food preservatives (Sarikaya and Cakir, 2005).

Potassium nitrate $\left(\mathrm{KNO}_{3}\right)$ is widely used as fertilizer in agriculture and, due to its oxidative properties, in many industrial processes. Potassium nitrate is found in drinking water, vegetables and, as E252, is widely utilized in the food industry as a preservative in the curing of meat (Sebranek and Bacus, 2007). However, high doses of nitrates and nitrites (and their metabolic products) are carcinogenic in humans due to the formation of nitrosamines (Camargo et al., 2005). Exposure of HEp- 2 cells to nitrates resulted in increased expression of genes associated with a stress response, cell cycle control and DNA repair (Bharadwaj et al., 2005). The acute toxicity of potassium nitrate was measured in juvenile blue swimmer crabs, histopathological changes to the anterior gill lamellae were observed, including lamellae swelling, epithelial thickening, pillar cell disruption, necrosis, and distortion 
(Romano and Zeng, 2007). Epidemiological studies have suggested that high nitrate levels in drinking water are associated with conditions such as teratogenicity, thyroid hypersensitivity and childhood diabetes (Bharadwaj et al., 2005). The main toxic effect of chronic nitrate is due to the conversion of haemoglobin to methaemoglobin which leads to methaemoglobinemia (Van Dijk et al., 1983). Patients administered nitrates display enhanced nitric oxide bioavailability in the vasculature, vasodilation effects, and inhibition of platelet aggregation. Administration of potassium nitrate $\left(0.06-0.35 \mathrm{mmol} \mathrm{kg}{ }^{-1} \mathrm{day}^{-1}\right)$ reduces diastolic and systolic blood pressure (Lonberg et al., 2008). Sodium nitrate also reduces blood pressure but leads to a reduction in oxygen consumption and increased blood flow (Lonberg et al., 2008).

The aim of the work presented here was to characterize the acute effect of potassium nitrate on $G$. mellonella larvae when administered by intra-haemocoel injection in order to establish a correlation with its effects in mammals. The development of an insect based screening system for measuring the relative toxicity of preservatives could contribute to reducing the need to use mammals for this type of testing.

\section{Materials and methods}

\subsection{Chemicals}

All chemicals and reagents were of the highest purity and quality and were purchased from Sigma Aldrich Co. Ltd., Dorset, United Kingdom, unless otherwise stated.

\subsection{G. mellonella larvae}

Larvae of the sixth developmental stage of $G$. mellonella were obtained from the Meal Worm Company (Sheffield, England). Larvae were stored in wood shavings in the dark at $15{ }^{\circ} \mathrm{C}$ prior to use and larvae weighing $0.22 \pm 0.03 \mathrm{~g}$ were used within two weeks of receipt. Ten healthy larvae per treatment and controls $(n=3)$ were placed in sterile nine $\mathrm{cm}$ Petri dishes lined with Whatman filter paper and containing some wood shavings.

\subsection{G. mellonella intra-haemocoel inoculation}

Potassium nitrate was dissolved in PBS ( $\mathrm{NaCl} 8.0 \mathrm{~g} / \mathrm{l} ; \mathrm{KCl} 0.2 \mathrm{~g} / \mathrm{l}$; $\mathrm{Na}_{2} \mathrm{HPO}_{4} 1.15 \mathrm{~g} / \mathrm{l} ; \mathrm{KH}_{2} \mathrm{PO}_{4} 0.5 \mathrm{~g} / \mathrm{l} ; \mathrm{pH} 7.3$ ) and diluted to the required concentration. Previous work has demonstrated that the lethal dose $25\left(\mathrm{LD}_{25}\right)$ of potassium nitrate in $G$. mellonella larvae was $1.52 \times 10^{-5} \mathrm{M}$, the lethal dose $50\left(\mathrm{LD}_{50}\right)$ was $1.8 \times 10^{-5} \mathrm{M}$ and the lethal dose $80\left(\mathrm{LD}_{80}\right)$ was $1.9 \times 10^{-5} \mathrm{M}$ (Maguire et al., 2016). Samples $(20 \mu \mathrm{l})$ were injected into the $\mathrm{G}$. mellonella haemocoel through the last left pro-leg using a myjector syringe (Terumo Europe) as described previously (Cotter et al., 2000). Controls received $20 \mu \mathrm{l}$ of PBS only. The inoculated larvae were incubated at $30^{\circ} \mathrm{C}$ for 4 or $24 \mathrm{~h}$. For assessment of larval viability, larvae were gently probed with a blunt ended needle and if no response was observed, the larvae were considered to be dead.

\subsection{Haemocyte isolation and enumeration}

Larvae were bled through the anterior region and resulting haemolymph was collected in sterile PBS. Following haemolymph collection haemocytes were separated by centrifugation at $500 \times \mathrm{g}$ for 5 min and subsequently washed twice in PBS to remove excess haemolymph. Cells were collected by centrifugation and resuspended in PBS supplemented with $5 \mathrm{mM}$ glucose. The concentration of cells was determined by haemocytometry and cellular viability was assessed using the trypan blue exclusion assay.

\subsection{Assessment of fungicidal ability of haemocytes}

Larvae were administered the $\operatorname{LD}_{50}\left(1.8 \times 10^{-5} \mathrm{M}\right)$ of potassium nitrate and after $24 \mathrm{~h}$ incubation at $30^{\circ} \mathrm{C}$ haemocytes were extracted and enumerated. Haemocytes $\left(1 \times 10^{6}\right)$ were mixed in a ratio of $1: 2$ with haemolymph-opsonized Candida albicans cells in a final volume of $2 \mathrm{ml}$ and incubated in a stirred chamber at $30^{\circ} \mathrm{C}$ (Bergin et al., 2005). Aliquots were removed at $t=0,20,40,60$ and $80 \mathrm{~min}$ and serially diluted in ice cold minimal essential medium to quench phagocytosis, prior to plating on YEPD agar plates ( $2 \% \mathrm{w} / v$ glucose, $2 \% \mathrm{w} / v$ peptone, $1 \% \mathrm{w} / \mathrm{v}$ yeast extract and $2 \% \mathrm{w} / \mathrm{v}$ agar) to ascertain fungal viability. The percentage reduction in yeast cell viability was calculated based on viability of control which was recorded as $100 \%$ as $t=0$.

\subsection{Determination of enzymatic activities}

\subsubsection{Catalase activity}

Larvae were administered $1.8 \times 10^{-5} \mathrm{M}$ potassium nitrate and catalase activity in haemocyte-free haemolymph was determined after 4 and $24 \mathrm{~h}$ as described previously (Rowan et al., 2009). Protein was extracted from larvae and the protein extract $(100 \mu \mathrm{l}, 7 \mathrm{mg} / \mathrm{ml})$ was added to $1.8 \mathrm{ml}$ of $17 \mathrm{mM} \mathrm{H}_{2} \mathrm{O}_{2}$ in a sterile tube. The mixture was mixed well and left at room temperature for $15 \mathrm{~min}$. After this time, the supernatant was removed and placed in a clean quartz cuvette. The absorbance at $240 \mathrm{~nm}$ was obtained using Beckman DU640 spectrophotometer. A blank consisted of $17 \mathrm{mM} \mathrm{H}_{2} \mathrm{O}_{2}$.

\subsubsection{Superoxide dismutase activity}

Larvae were administered $1.8 \times 10^{-5} \mathrm{M}$ potassium nitrate and total superoxide dismutase (SOD) activity in haemocyte-free haemolymph was determined at $24 \mathrm{~h}$ by assaying the oxidation of quercetin by $N, N$ ', $N$-tetramethyl-ethylenediamine and the absorbance at $406 \mathrm{~nm}$ for 5 min was obtained. One-unit total SOD activity was calculated as the amount of protein causing $50 \%$ inhibition of quercetin oxidation (Buyukguzel et al., 2013) and total SOD activity was expressed as units per microgram of protein.

\subsection{Extraction of haemocytes for Fluorescence-activated cell sorting (FACS) analysis}

Haemolymph was extracted from larvae that had been administered $1.8 \times 10^{-5} \mathrm{M}$ of potassium nitrate and diluted in ice cold PBS. Haemocytes were enumerated and the density was adjusted to $1 \times 10^{6}$ cells $/ \mathrm{ml}$. Cells were fixed in $4 \%$ formaldehyde (Sigma-Aldrich) in PBS for $10 \mathrm{~min}$ at $4{ }^{\circ} \mathrm{C}$. Haemocytes were washed in $1 \%$ BSA/PBS, $1500 \times \mathrm{g}$ for $5 \mathrm{~min}$ at $4^{\circ} \mathrm{C}$ and re-suspended in BSA/PBS at a density of $1 \times 10^{6}$ cells $/ \mathrm{ml}$. Haemocyte populations were characterized using a FACSAria (Becton Dickinson) flow cytometer and cells were differentiated based on side and forward scatter with a total of 10,000 events measured per sample (Browne et al., 2015). Analysis was performed on three independent occasions.

\subsection{Label free quantitative proteomics of larval haemolymph}

Label free shotgun quantitative proteomics was conducted on haemocyte-free haemolymph from larvae administered $1.8 \times 10^{-5} \mathrm{M}$ potassium nitrate after $24 \mathrm{~h}$ incubation. Protein $(75 \mu \mathrm{g})$ was reduced with dithiothreitol (DTT; $200 \mathrm{mM}$ ), alkylated with iodoacetamide (IAA; $1 \mathrm{M}$ ) and digested with sequence grade trypsin (Promega, Ireland) at a trypsin: protein ratio of $1: 40$, overnight at $37^{\circ} \mathrm{C}$. Tryptic peptides were purified for mass spectrometry using C18 spin filters (Medical Supply Company, Ireland) and $1 \mu \mathrm{g}$ of peptide mix was eluted onto a QExactive (ThermoFisher Scientific, U.S.A.) high resolution accurate mass spectrometer connected to a Dionex Ultimate 3000 (RSLCnano) chromatography system. Peptides were separated by an increasing acetonitrile gradient on a Biobasic C18 Picofrit ${ }^{\mathrm{TM}}$ column 
(100 mm length, $75 \mathrm{~mm}$ ID), using a $120 \mathrm{~min}$ reverse phase gradient at a flow rate of $250 \mathrm{~nL} / \mathrm{min}$. All data were acquired with the mass spectrometer operating in automatic data dependent switching mode. A high resolution mass spectrometer (MS) scan (300-2000 Da) was performed using the Orbitrap to select the 15 most intense ions prior to MS/MS.

Protein identification from the MS/MS data was performed using the Andromeda search engine in MaxQuant (version 1.2.2.5; http:// maxquant.org/) (Cox et al., 2011) to correlate the data against a 6frame translation of the EST contigs for G. mellonella (Vogel et al., 2011). The following search parameters were used: first search peptide tolerance of $20 \mathrm{ppm}$, second search peptide tolerance $4.5 \mathrm{ppm}$ with cysteine carbamidomethylation as a fixed modification and $\mathrm{N}$-acetylation of protein and oxidation of methionine as variable modifications and a maximum of 2 missed cleavage sites allowed. False Discovery Rates (FDR) were set to $1 \%$ for both peptides and proteins and the FDR was estimated following searches against a target-decoy database. Peptides with minimum length of seven amino acid length were considered for identification and proteins were only considered identified when more than one unique peptide for each protein was observed.

Results processing, statistical analyses and graphics generation were conducted using Perseus v. 1.5.0.31. LFQ intensities were log2-transformed and ANOVA of significance and t-tests between the haemolymph proteomes of control and potassium nitrate treated larvae was performed using a $p$-value of 0.05 and significance was determined using FDR correction (Benjamini-Hochberg). Proteins that had non-existent values (indicative of absence or very low abundance in a sample) were included in the study only when they were completely absent from one group and present in at least three of the four replicates in the second group (referred to as qualitatively differentially abundant proteins). The Blast2GO suite of software tools was utilized to assign gene ontology terms ( $\mathrm{GO}$ terms) relating to biological processes (BP) and molecular function (MF).

\subsection{Statistical analysis}

All experiments were performed on three independent occasions and results are expressed as the mean \pm SE. Changes in larval survival were analysed with the log rank (Mantel-Cox) method. Analysis of changes in haemocyte density was performed by One-way ANOVA. Differences were considered significant at $p<0.05$.

\section{Results}

\subsection{Effect of potassium nitrate on haemocyte density and function}

Larvae were administered three potassium nitrate concentrations corresponding to the $\mathrm{LD}_{25}, \mathrm{LD}_{50}$ or $\mathrm{LD}_{80}$ values as described and the effect on the density of circulating haemocytes was ascertained after $24 \mathrm{~h}$. Larvae administered the $\mathrm{LD}_{50}$ and $\mathrm{LD}_{80}$ demonstrated a 1.9 fold and a 2.5 fold increase $(p<0.001)$ in circulating haemocytes, respectively (Fig. 1). FACS analysis was employed to establish if there was a change in the relative proportion of each haemocyte sub-population in larvae administered $1 \times 10^{-8} \mathrm{M}$ potassium nitrate compared to control larvae. Haemocyte populations were differentiated on the basis of size and granularity and at least six distinct sub-populations, labelled P1 to P6, were identified (Fig. 2). Larvae administered potassium nitrate showed a significant decrease $(p<0.05)$ in the relative abundance of P1 haemocytes (small, granular cells). The total percentage of the P1 subpopulation of haemocytes in control larvae was $58.42 \% \pm 0.47$ and $50.06 \pm 2.0$ in larvae administered potassium nitrate. There was a small increase in the P2 (very small granular cells) and P4 and P5 (large and granular) populations of haemocytes and a small decrease in the population of P6 haemocytes (large granular) in larvae that received potassium nitrate. However, haemocytes isolated from larvae administered potassium nitrate $\left(1.8 \times 10^{-5} \mathrm{M}\right)$ showed a reduced ability to kill C. albicans cells (Fig. 3). At 80 min haemocytes from control larvae

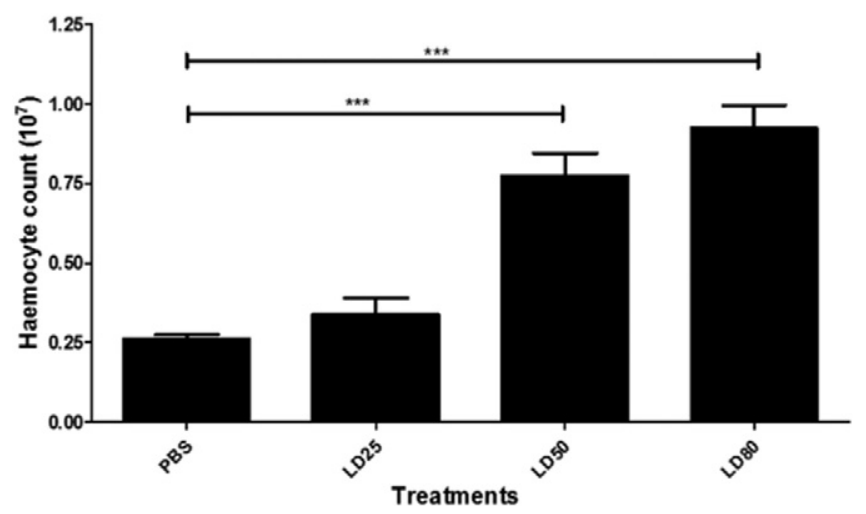

Fig. 1. Effect of potassium nitrate on haemocyte density in G. mellonella larvae. Larvae were administered potassium nitrate $\operatorname{LD}_{25}\left(1.52 \times 10^{-5} \mathrm{M}\right)$, $\mathrm{LD}_{50}\left(1.8 \times 10^{-5} \mathrm{M}\right)$ and $\mathrm{LD}_{80}$ $\left(1.9 \times 10^{-5} \mathrm{M}\right)$. The haemocyte density was calculated after $24 \mathrm{~h}\left({ }^{* * *}: p<0.001\right)$. All values are the mean \pm SE of 3 independent determinations.

had reduced the population of viable yeast cells by over $90 \%$ while haemocytes from larvae that received potassium nitrate reduced yeast viability by $40 \%$ at the same timepoint (Fig. 3 ).

\subsection{Effects of potassium nitrate on the enzymatic activity in G. mellonella haemolymph}

Larvae were administered $1.8 \times 10^{-5} \mathrm{M}$ potassium nitrate $\left(\mathrm{LD}_{50}\right.$ value) and the catalase and superoxide dismutase activities in haemolymph were measured. There was a slight reduction in catalase activity at $24 \mathrm{~h}$ but this was not deemed statistically significant. Haemolymph extracted from larvae administered potassium nitrate showed significant change in superoxide dismutase activity after $24 \mathrm{~h}$ : 1 unit of superoxide dismutase activity equated to $231.1 \pm 29.69 \mu \mathrm{g} / \mu \mathrm{l}$ in control larvae but $100.6 \pm 19.63 \mu \mathrm{g} / \mu \mathrm{l}$ in haemolymph from potassium nitrate injected larvae $(p<0.05)$.

\subsection{Effect of potassium nitrate on haemolymph proteome}

Label free quantitative proteomics was performed on haemolymph from larvae administered the $\mathrm{LD}_{50}$ of potassium nitrate $\left(1.8 \times 10^{-5} \mathrm{M}\right)$ for $24 \mathrm{~h}$. In total 525 peptides were identified representing 167 proteins with two or more peptides (Fig. 4). Forty one proteins ( 32 proteins imputated and 9 proteins non-imputated) were significantly increased in abundance in larvae administered potassium nitrate compared to control larvae (Table 1). The protein showing the highest increase in abundance in larvae exposed to potassium nitrate was beta actin with a fold increase of $47.9(p<0.05)$, while the proteins highest in abundance with an imputated value were mitochondrial aldehyde dehydrogenase ( 288.6 fold increase), beta-tubulin (283.1 fold increase), aliphatic nitrilase (132.5 fold increase), triosephosphate isomerase enolase ( 79.8 fold increase) and alcohol dehydrogenase precursor ( 52.8 fold increase) (Table 1 ). A number of related proteins were observed at increased abundance in larvae administered potassium nitrate, including a number of dehydrogenases and transferases (mitochondrial aldehyde dehydrogenase (288.6 fold increase), alcohol dehydrogenase precursor (52.8 fold increase), cytosolic malate dehydrogenase (46.2 fold), glyceraldehyde-3-phosphate dehydrogenase (20.3 fold increase), zinc-containing alcohol dehydrogenase (16.9 fold increase), serine hydroxymethyltransferase (12.1 fold increase) short-chain dehydrogenase/reductase (12.2 fold increase), isocitrate dehydrogenase ( 2.3 fold increase), glutathione $S$-transferase (20.6 fold increase)) and serine hydroxymethyltransferase (12.1 fold increase). Numerous proteins involved in mitochondrial function (e.g. mitochondrial aldehyde dehydrogenase, putative mitochondrial Mn superoxide dismutase ( 15.2 fold increase), cytosolic malate dehydrogenase (46.2 fold increase), triosephosphate isomerase (37.1 fold 


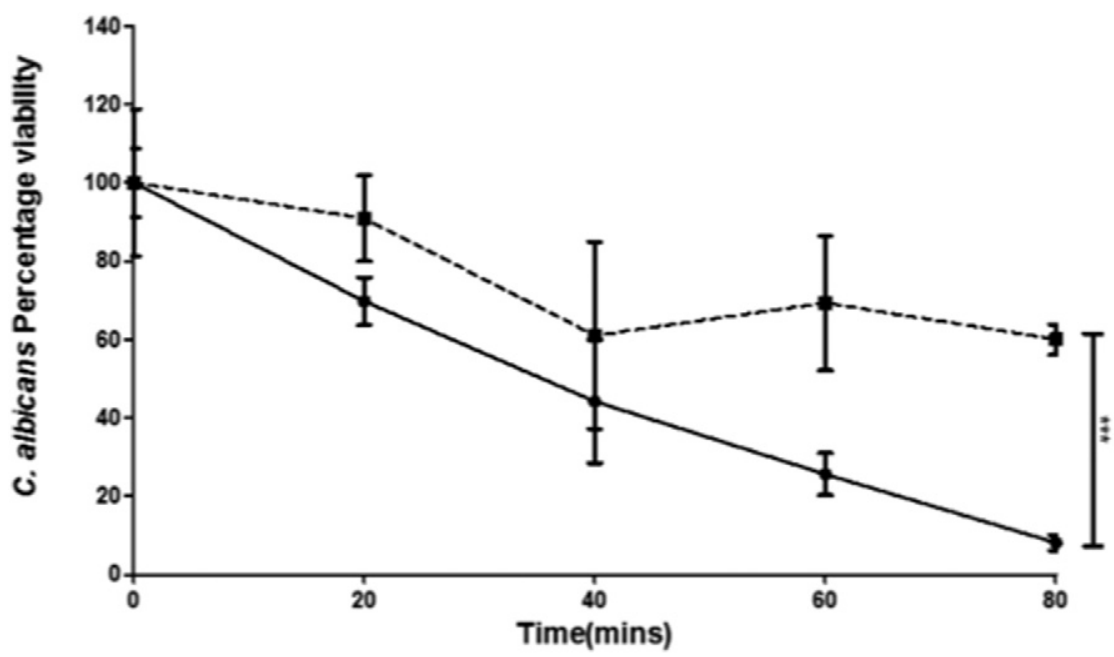

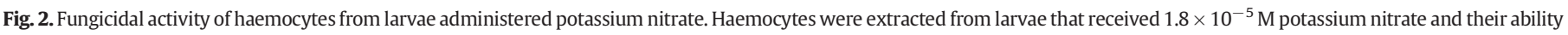

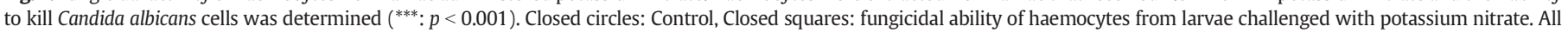
values are the mean \pm SE of 3 independent determinations.

increase), enolase (62.4 fold increase) and glyceraldehyde-3-phosphate dehydrogenase ( 9.7 fold increase)) were present at a higher abundance in larvae exposed to potassium nitrate. Proteins decreased in abundance in larvae that received potassium nitrate included putative protease inhibitor 4 (1.9 fold decrease), imaginal disc growth factor (1.7 fold decrease), kazal-type proteinase inhibitor precursor (1.6 fold decrease), twelve cysteine protein 1 (1.5 fold decrease) and carboxylesterase CarE-7 (1.5 fold decrease) (Table 2).

Blast2GO annotation software was used to group proteins based on conserved GO terms in order to identify processes and pathways potentially associated with potassium nitrate metabolism. GO terms were categorized by biological processes and molecular function. The greatest increase in BP included proteins labelled as cellular metabolic process (11 proteins in control - 18 proteins in treated larvae), nitrogen compound metabolic process $(8-13)$, organic substance metabolic process $(10-21)$ and primary metabolic process $(9-18)$, single-organism cellular process ( 9 - 16) and single organism metabolic process $(8-19)$ (Fig. 5). Proteins labelled as molecular function level 3 showing increased abundance in larvae administered potassium nitrate included heterocyclic compound binding ( 7 proteins in control larvae - 11 protein in treated larvae), hydrolase activity (7 - 13), organic cyclic compound binding ( $7-11)$, oxidoreductase activity (4 - 12) and small molecular binding $(8-12)$ (Fig. 6).

\section{Discussion}

Administration of potassium nitrate to $G$. mellonella larvae by intrahaemocoel injection leads to an increase in the density of circulating haemocytes but only small changes in the relative proportions of the haemocyte subpopulations. Larvae administered potassium nitrate showed a significant decrease in the relative abundance of P1 haemocytes (small, granular cells). There was a small increase in the P2 (very small granular cells), P4 and P5 (large and granular) populations and a small decrease in the population of P6 (large granular) population. Haemocytes from larvae administered potassium nitrate showed a significant $(p<0.05)$ reduction in their fungicidal killing ability compared with haemocytes extracted from control larvae. The changes in the relative proportion of haemocyte sub-populations would be insufficient to account for this decline in fungicidal ability. Elevated density of circulating haemocytes following physical (Mowlds et al., 2008) or thermal (Mowlds and Kavanagh, 2008) stress was associated with resistance to subsequent infection. However it has been

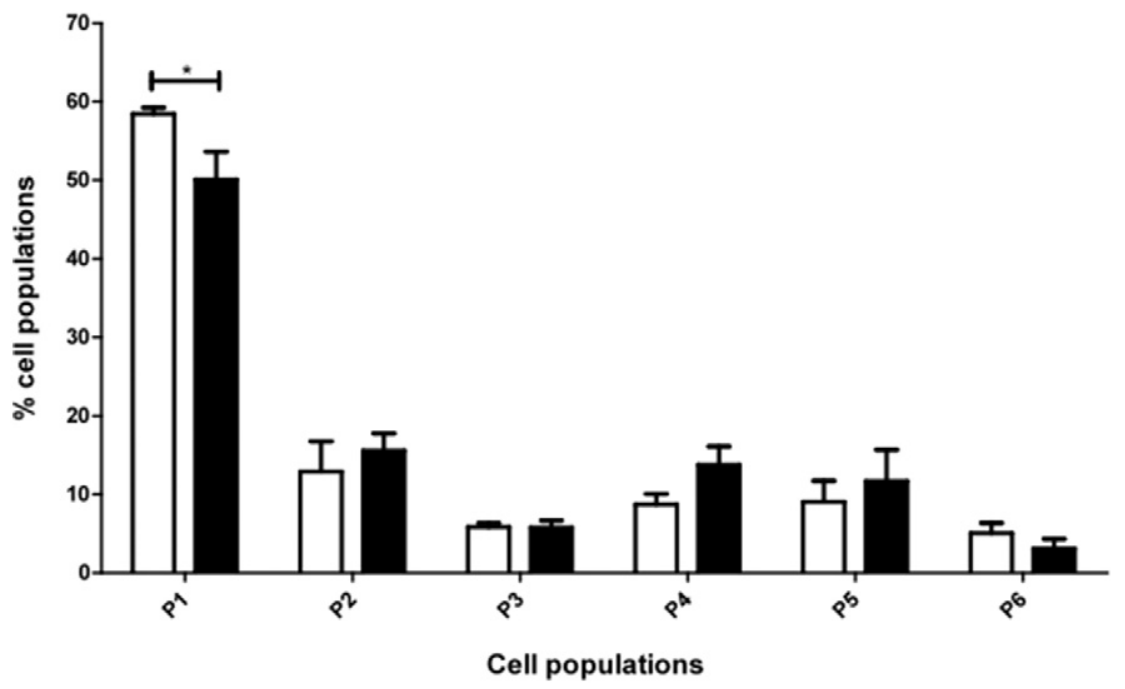

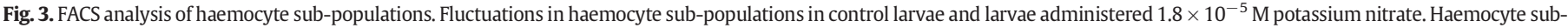

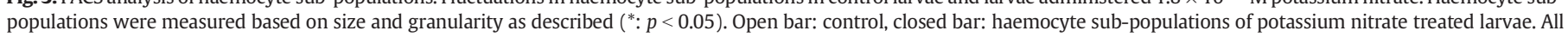
values are the mean \pm SE of 3 independent determinations. 


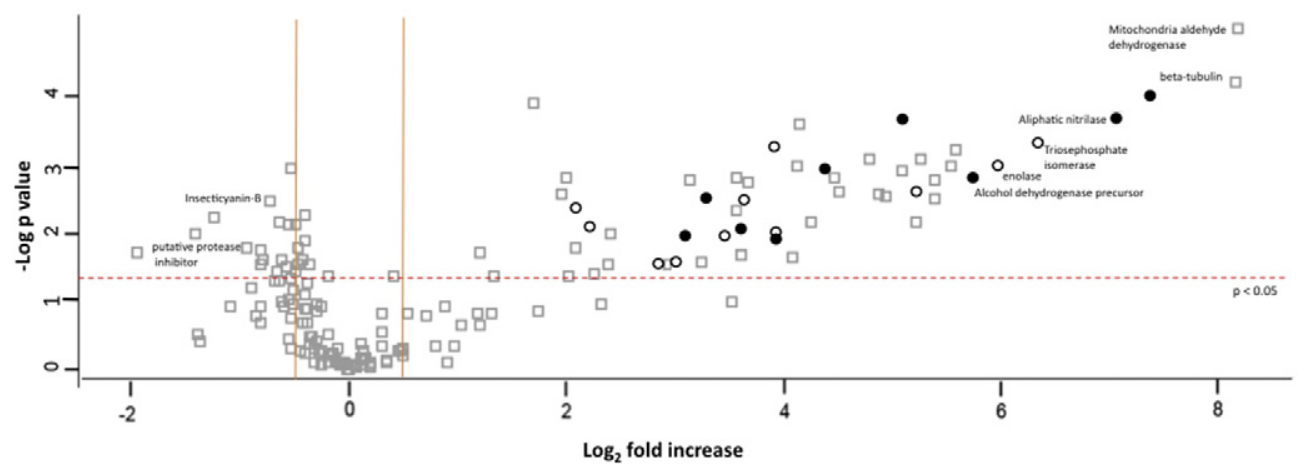

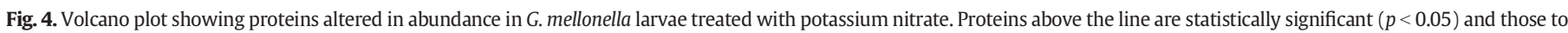

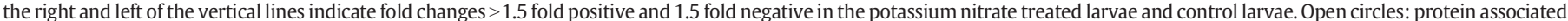
with metabolism, closed circles proteins associated with metabolism and oxidoreductase activity, squares all other proteins.

demonstrated that sodium nitrate inhibits the formation of ROS by activated murine neutrophils and macrophages (Deriagina et al., 2003) and inhibition of ROS formation may be due to NO interference with the membrane component of the NADPH oxidase (Clancy et al., 1992). Human neutrophils and insect haemocytes display many similarities (Browne et al., 2013) including the ability to produce superoxide by a functional NADPH oxidase complex (Bergin et al., 2005). Haemocytes from larvae injected with potassium nitrate may also display a reduced ability to kill C. albicans cells due to suppressed superoxide production.

Nitrates interact with mitochondrial function and modulate oxidative stress (Lundberg et al., 2011). A balanced antioxidant enzyme system against reactive oxygen/nitrogen species is present in cells;

Table 1

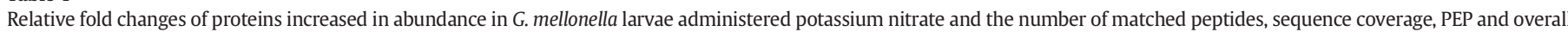

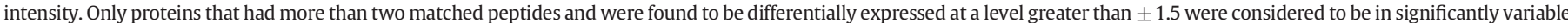
abundances between control and treated larvae.

\begin{tabular}{|c|c|c|c|c|c|}
\hline Protein name $(*=$ imputated protein $)$ & Peptides & $\begin{array}{l}\text { Sequence coverage } \\
{[\%]}\end{array}$ & PEP & $\begin{array}{l}\text { Mean LFQ } \\
\text { intensity }\end{array}$ & $\begin{array}{l}\text { Fold } \\
\text { difference }\end{array}$ \\
\hline${ }^{*}$ Mitochondrial aldehyde dehydrogenase & 30 & 64.5 & 0 & $1.20 \mathrm{E}+11$ & 288.64 \\
\hline${ }^{*}$ Beta-tubulin & 17 & 31.7 & 0 & $5.92 \mathrm{E}+10$ & 283.14 \\
\hline${ }^{*}$ Aliphatic nitrilase & 19 & 53 & 0 & $7.06 \mathrm{E}+10$ & 132.52 \\
\hline${ }^{*}$ Triosephosphate isomerase & 18 & 30.1 & 0 & $1.97 \mathrm{E}+10$ & 79.80 \\
\hline *Enolase & 18 & 43 & 0 & $1.40 \mathrm{E}+10$ & 62.48 \\
\hline *Alcohol dehydrogenase precursor & 13 & 45.2 & $1.4106 \mathrm{E}-167$ & $1.32 \mathrm{E}+10$ & 52.88 \\
\hline Beta actin & 11 & 52.7 & 0 & $8.66 \mathrm{E}+10$ & 47.90 \\
\hline${ }^{*}$ Cytosolic malate dehydrogenase & 15 & 34.4 & $2.1709 \mathrm{E}-143$ & $1.17 \mathrm{E}+10$ & 46.20 \\
\hline *AAEL005062-PA & 9 & 26.5 & $3.5948 \mathrm{E}-74$ & $1.14 \mathrm{E}+10$ & 41.93 \\
\hline *Alpha 2-tubulin, partial & 4 & 47.2 & 0 & $1.84 \mathrm{E}+10$ & 38.11 \\
\hline${ }^{*}$ Triosephosphate isomerase & 9 & 17.4 & 0 & $7.81 \mathrm{E}+09$ & 37.19 \\
\hline${ }^{*}$ Thioredoxin-like protein & 5 & 20.4 & $3.5015 \mathrm{E}-59$ & $7.57 \mathrm{E}+09$ & 33.97 \\
\hline *Actin 3 & 8 & 29.1 & 0 & $1.04 \mathrm{E}+10$ & 29.17 \\
\hline *Elongation factor 1 alpha & 9 & 34 & $1.6052 \mathrm{E}-198$ & $1.03 \mathrm{E}+10$ & 21.98 \\
\hline${ }^{*}$ Glutathione $S$-transferase & 10 & 41.1 & $7.1188 \mathrm{E}-140$ & $8.03 \mathrm{E}+09$ & 20.63 \\
\hline Glyceraldehyde-3-phosphate dehydrogenase & 13 & 49.4 & 0 & $7.07 \mathrm{E}+10$ & 20.36 \\
\hline${ }^{*}$ Glutathione-S-transferase-like protein & 10 & 47.2 & 0 & $9.43 \mathrm{E}+09$ & 17.68 \\
\hline${ }^{*}$ Chemosensory protein & 4 & 14 & $1.7008 \mathrm{E}-91$ & $7.56 \mathrm{E}+09$ & 17.29 \\
\hline *Zinc-containing alcohol dehydrogenase & 11 & 44.4 & 0 & $8.68 \mathrm{E}+09$ & 16.97 \\
\hline *Putative mitochondrial Mn superoxide dismutase & 9 & 45.5 & $2.9836 \mathrm{E}-281$ & $7.23 \mathrm{E}+09$ & 15.20 \\
\hline $\begin{array}{l}\text { *Phosphoribosylaminoimidazole carboxylase, phosphoribosylaminoimidazole } \\
\text { succinocarboxamide synthetase }\end{array}$ & 19 & 37.2 & $4.6317 \mathrm{E}-271$ & $1.29 \mathrm{E}+10$ & 15.13 \\
\hline${ }^{*}$ Cyclophilin-like protein & 6 & 24.7 & $4.1192 \mathrm{E}-168$ & $5.47 \mathrm{E}+09$ & 15.02 \\
\hline Cellular retinoic acid binding protein & 15 & 35.6 & $7.0508 \mathrm{E}-292$ & $7.31 \mathrm{E}+10$ & 12.77 \\
\hline Arginine kinase, partial & 10 & 71.1 & $3.7151 \mathrm{E}-203$ & $3.40 \mathrm{E}+10$ & 12.35 \\
\hline *Short-chain dehydrogenase/reductase & 8 & 30 & $8.537 \mathrm{E}-302$ & $3.43 \mathrm{E}+09$ & 12.22 \\
\hline *Serine hydroxymethyltransferase & 21 & 43.3 & $3.6909 E-238$ & $1.27 \mathrm{E}+10$ & 12.15 \\
\hline${ }^{*}$ Heat shock protein hsp21.4 & 6 & 15.4 & $6.3966 \mathrm{E}-115$ & $5.09 \mathrm{E}+09$ & 11.74 \\
\hline${ }^{*}$ Serine protease inhibitor 5 precursor & 11 & 31.2 & $2.416 \mathrm{E}-49$ & $3.12 \mathrm{E}+09$ & 10.98 \\
\hline *Glyceraldehyde-3-phosphate dehydrogenase & 11 & 39.2 & 0 & $7.57 \mathrm{E}+09$ & 9.74 \\
\hline${ }^{*}$ Muscle protein 20 -like protein & 12 & 39.7 & $1.7499 \mathrm{E}-185$ & $4.96 \mathrm{E}+09$ & 8.70 \\
\hline *AAEL000132-PA & 6 & 47.8 & $4.0548 \mathrm{E}-86$ & $2.57 \mathrm{E}+09$ & 8.51 \\
\hline *Tropomyosin 2 & 8 & 35.9 & $2.7637 \mathrm{E}-91$ & $2.08 \mathrm{E}+09$ & 7.58 \\
\hline RecName: Full = Seroin; AltName: Full = Silk 23 kDa glycoprotein; Flags: Precursor & 3 & 16.2 & $1.0038 \mathrm{E}-121$ & $6.29 \mathrm{E}+09$ & 5.33 \\
\hline *14-3-3zeta & 3 & 4.6 & $1.2498 \mathrm{E}-295$ & $2.20 \mathrm{E}+09$ & 5.21 \\
\hline *Prophenol oxidase activating enzyme 3 & 10 & 25.4 & $1.4735 \mathrm{E}-51$ & $1.46 \mathrm{E}+09$ & 4.76 \\
\hline${ }^{*}$ Cathepsin B-like cysteine proteinase & 6 & 19.6 & $8.7962 E-35$ & $1.99 \mathrm{E}+09$ & 4.63 \\
\hline Abnormal wing disc-like protein & 9 & 46.9 & $8.0549 \mathrm{E}-169$ & $1.05 \mathrm{E}+10$ & 4.22 \\
\hline AGAP010733-PA, partial & 4 & 15.3 & $3.6022 \mathrm{E}-27$ & $1.87 \mathrm{E}+09$ & 3.90 \\
\hline *Heat shock-like protein, partial & 3 & 17.7 & $2.0202 \mathrm{E}-20$ & $1.81 \mathrm{E}+09$ & 3.24 \\
\hline Heat shock protein 25.4 precursor & 11 & 47.2 & 0 & $4.92 \mathrm{E}+10$ & 2.51 \\
\hline Isocitrate dehydrogenase & 17 & 48.2 & 0 & $1.78 \mathrm{E}+10$ & 2.31 \\
\hline
\end{tabular}


Table 2

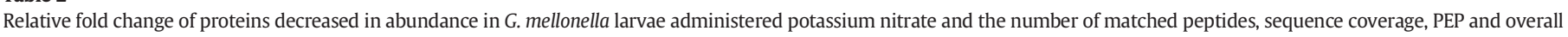

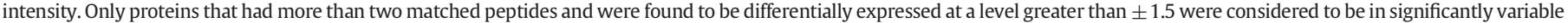
abundances between control and treated larvae.

\begin{tabular}{|c|c|c|c|c|c|}
\hline $\begin{array}{l}\text { Protein name } \\
\left({ }^{*}=\text { imputated protein }\right)\end{array}$ & Peptides & $\begin{array}{l}\text { Sequence coverage } \\
{[\%]}\end{array}$ & PEP & $\begin{array}{l}\text { Mean LFQ } \\
\text { intensity }\end{array}$ & $\begin{array}{l}\text { Fold } \\
\text { difference }\end{array}$ \\
\hline Putative protease inhibitor 4 & 7 & 25.7 & $9.239 \mathrm{E}-288$ & $7.00 \mathrm{E}+10$ & -1.91 \\
\hline Anopheles gambiae str. PEST AGAP012658-PA & 11 & 47.3 & $7.915 \mathrm{E}-85$ & $1.28 \mathrm{E}+10$ & -1.75 \\
\hline Imaginal disc growth factor & 16 & 51.9 & 0 & $7.00 \mathrm{E}+11$ & -1.75 \\
\hline $\begin{array}{l}\text { RecName: Full = Insecticyanin-B; Short = INS-b; AltName: Full = Blue biliprotein; Flags: } \\
\text { Precursor }\end{array}$ & 14 & 45.5 & 0 & $1.96 \mathrm{E}+11$ & -1.65 \\
\hline Kazal-type proteinase inhibitor precursor & 8 & 21.4 & $1.4788 \mathrm{E}-224$ & $5.80 \mathrm{E}+10$ & -1.61 \\
\hline Twelve cysteine protein 1 & 10 & 43.4 & 0 & $3.10 \mathrm{E}+10$ & -1.59 \\
\hline Carboxylesterase CarE-7 & 6 & 42.9 & $1.096 \mathrm{E}-232$ & $2.00 \mathrm{E}+10$ & -1.55 \\
\hline
\end{tabular}

catalase reduces $\mathrm{H}_{2} \mathrm{O}_{2}$ to water and oxygen and superoxide dismutase catalyzes the dismutation of superoxide radicals to $\mathrm{H}_{2} \mathrm{O}_{2}$ and oxygen, and appears to be the main response to dietary pro-oxidant exposure. There was no statistically significant change in the catalase activity (or in glutathione-S-transferase activity, data not shown) in haemolymph of larvae administered potassium nitrate. In contrast, a significant increase in superoxide dismutase activity $(p<0.05)$ was observed. Sydow et al. (2004) reported that nitroglycerin (GTN) administration increased the production of reactive oxygen species by mitochondria. In mammals the binding of NO to cytochrome $c$ oxidase causes a depolarization of the inner mitochondrial membrane and combined with an increase in the reduction state of the electron transport chain results in the generation of superoxide anions, which are subsequently converted to hydrogen peroxide by superoxide dismutase (Moncada and Erusalimsky, 2002). Proteomic analysis also showed the increased abundance of a putative mitochondrial Mn superoxide dismutase (15.2 fold increase) in larvae that received potassium nitrate.

Proteomic analysis revealed the increased abundance of a mitochondrial aldehyde dehydrogenase $(288.6$ fold $)(p<0.05)$ in larvae challenged with potassium nitrate. Chen et al. (2002) purified a nitrate reductase from mouse RAW264.7 cells that specifically catalyzes the formation of 1,2-glyceryl dinitrate (GDN) 1,3-GDN, inorganic nitrite and NO from organic nitrate (GTN), which mediates vasorelaxation.
This nitrate reductase was identified as the redox sensitive enzyme mitochondrial aldehyde dehydrogenase and it was also demonstrated that rabbit aorta made tolerant to GTN, showed a significantly decrease in GTN reductase activity (Chen et al., 2002). It has been previously shown that rabbits chronically treated with GTN demonstrate greater degrees of tolerance to GTN after three days exposure due to increased steady state concentrations of vascular $0^{-2}$ (Munzel et al., 1995). The finding presented here showed not only a 300 -fold $(p>0.05)$ increase of mitochondrial aldehyde dehydrogenase but the significant increase $(p>0.05)$ of superoxide dismutase activity in larvae challenged with potassium nitrate. These findings would suggest that both mammals and insects metabolise nitrates in a similar manner.

In G. mellonella larvae treated with potassium nitrate there was an increase in the abundance of a number of mitochondrial-associated proteins (e.g. mitochondrial aldehyde dehydrogenase (288.6 fold increase), putative mitochondrial Mn superoxide dismutase (15.2 fold increase), isocitrate dehydrogenase ( 2.3 fold increase) and cytosolic malate dehydrogenase ( 46.2 fold increase)). Multiple proteins involved in glycolysis and the Kreb's cycle were also shown to be increased in abundance such as triosephosphate isomerase ( 79.80 fold increase), glyceraldehyde 3 phosphate dehydrogenase (20.36 fold increase), enolase (62.8 fold increase) and isocitrate dehydrogenase (2.3 fold increase). Lundberg et al. (2011) reported that NO binds to cytochrome $c$ oxidase, the terminal

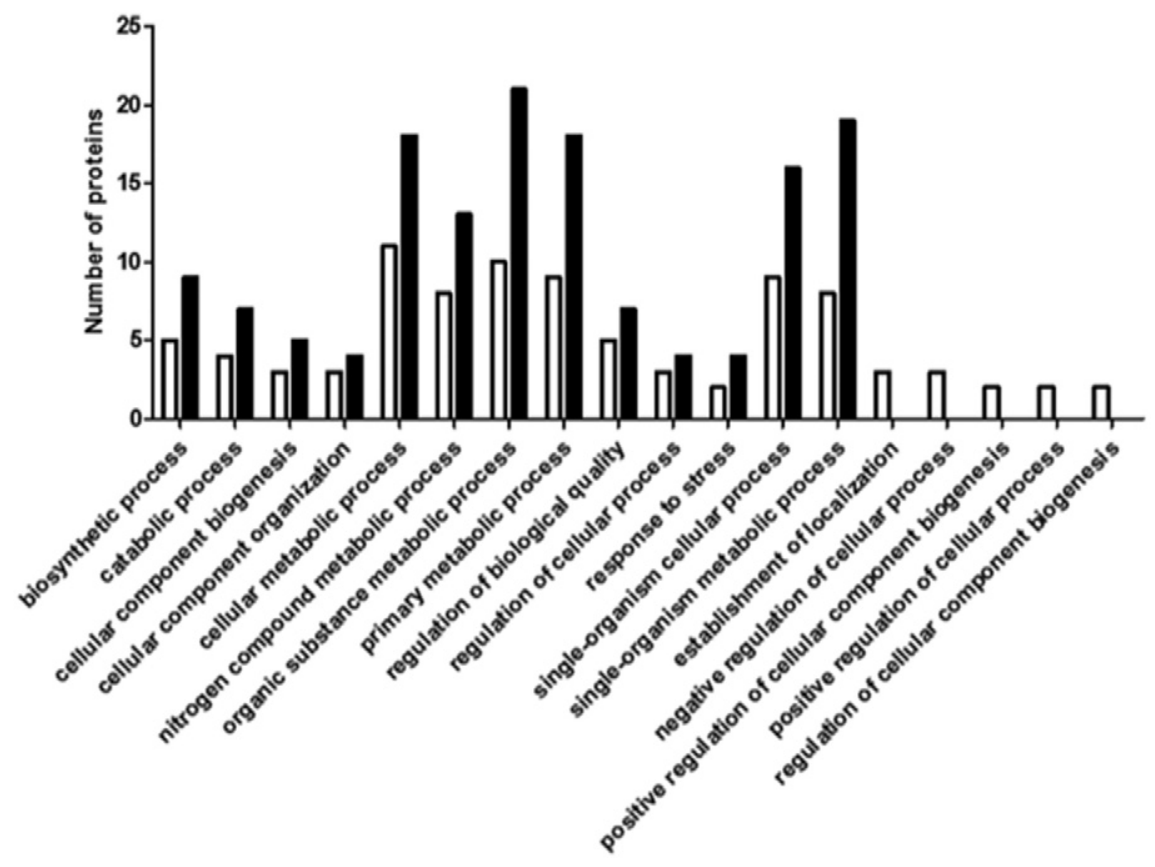

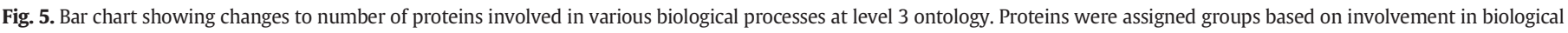

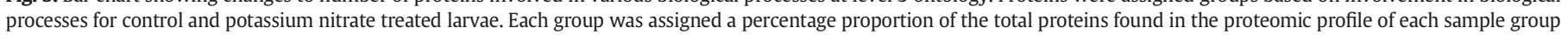
and graphed on a comparative bar chart. Open bar: control, closed bar: potassium nitrate treated larvae. 


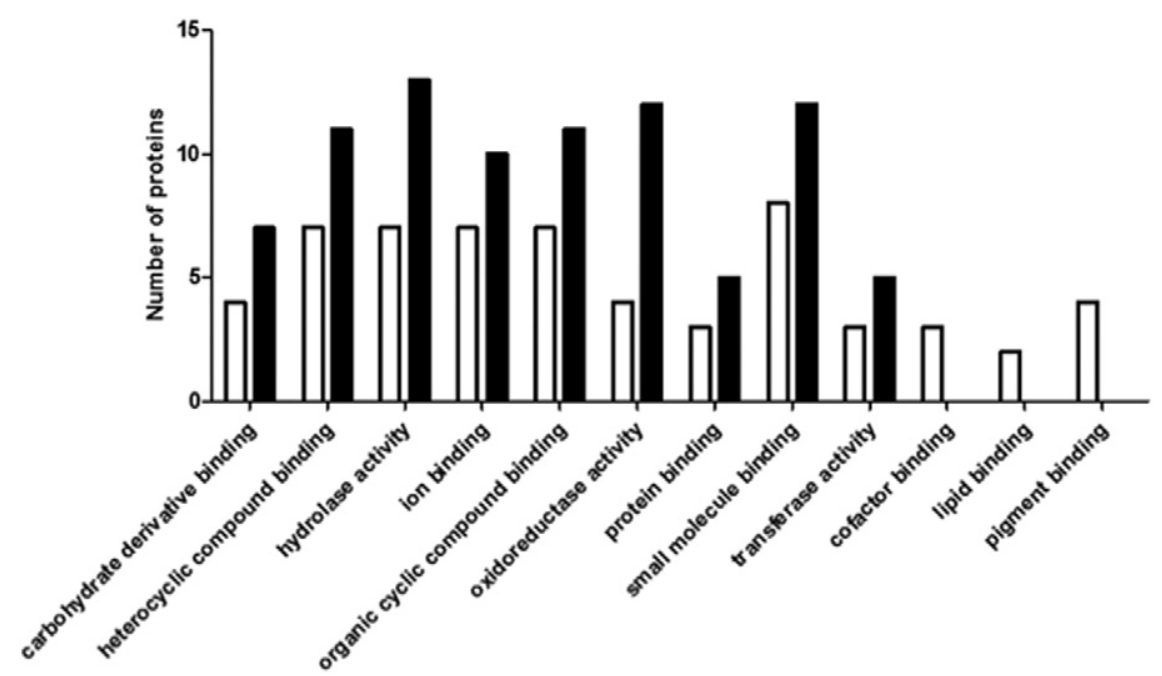

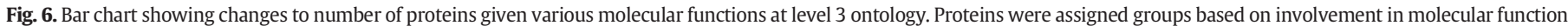

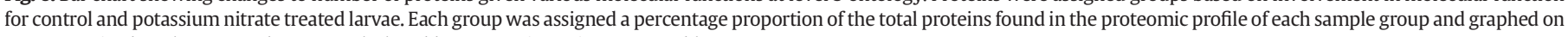
a comparative bar chart. Open bar: control, closed bar: potassium nitrate treated larvae.

respiratory complex in the mitochondrial electron transport chain, in competition with oxygen, reducing oxygen costs and extending time to exhaustion, perhaps due to a reduction in ATP cost of muscle force production or as a direct effect of the improved metabolic efficiency. $\mathrm{NO}$, through its interaction with components of the electron transport chain, may act as a physiological regulator of cell respiration and the inhibition of cytochrome $c$ oxidase by NO leads to an increase in the rate of glycolysis, ensuring a sufficient supply of glycolytic ATP to fuel the ATPase (Moncada and Erusalimsky, 2002). G. mellonella larvae challenged with potassium nitrate demonstrated an increase in proteins involved in oxidoreductase activity, together with significant increases in mitochondria associated proteins and proteins involved in glycolysis and the Krebs cycle suggesting that the response to potassium nitrate in larvae share similarities with the cell respiration regulatory responses of mammals challenged with potassium nitrate.

Endogenous levels of nitrates are necessary for the production of a diverse group of metabolites including nitric oxide, nitrosothiols and nitroalkenes and the subsequent regulation of vasodilation, blood pressure, inflammatory cell recruitment, and platelet aggregation (Hord, 2011). Dietary nitrate, nitrite and the amino acid L-arginine can serve as sources for the production of these metabolites via ultraviolet light exposure to skin, mammalian nitrate/nitrite reductases in tissues, and nitric oxide synthase enzymes. In larvae that received potassium nitrate there was an increase in the abundance of proteins associated with nitrate metabolism including mitochondrial aldehyde dehydrogenase (288.6 fold increase), aliphatic nitrilase (132.5 fold increase), enolase (62.4 fold increase) and glutathione $S$-transferase (20.6 fold increase). Chen et al. (2002) showed that mitochondrial aldehyde dehydrogenase specifically catalyzes the formation of 1,2-glyceryl dinitrate (GDN) 1,3GDN, inorganic nitrite and NO from the organic nitrate nitroglycerin.

Insects are widely used for assessing the virulence of microbial pathogens and for measuring the efficacy of antimicrobial drugs and can produce results comparable to those that can be obtained using mammals (Jander et al., 2000; Brennan et al., 2002). We have previously established a strong correlation between the toxicity of food preservatives in G. mellonella larvae and in rats (Maguire et al., 2016). In the work presented here the effect of one of these preservatives on larvae is characterized and many similarities with the effect in mammals are identified. Potassium nitrate reduced the killing ability of insect immune cells possibly by inhibiting superoxide production as it does in neutrophils (Clancy et al., 1992). Administration of the compound to larvae lead to elevated superoxide dismutase activity after $24 \mathrm{~h}$, an effect also observed in rats that develop sensitivity to organic nitrates
(Munzel et al., 1995). Proteomic analysis revealed increased abundance of mitochondrial associated proteins, in those involved in the oxidative stress response and in those involved in nitrate metabolism as seen in mammals (Moncada and Erusalimsky, 2002). Identifying similarities between the response of insects and mammals to preservatives and xenobiotics may assist in the development of novel insect-based screening systems to measure toxicity and identify modes of action which could accelerate research and lead to a reduction in the numbers of mammals required for this type of testing.

\section{Financial disclosures}

The authors have no financial conflicts to disclose.

\section{Conflicts of interest}

None to declare.

\section{Acknowledgement}

Q-Exactive mass spectrometer was funded under the SFI Research Infrastructure Call 2012; Grant Number: 12/RI/2346 (3).

\section{References}

Aneja, B., Ifran, M., Kapil, C., Jairajpuri, M., Maguire, R., Kavanagh, K., Rizvi, M., Manzoor, N. Azam, A., Abid, M., 2016. Effect of novel triazole-amino acid hybrids on growth and virulence of Candida species: in vitro and in vivo studies. Org. Biomol. Chem. 14, 10599-10619.

Bergin, D., Brennan, M., Kavangh, K., 2003. Fluctuations in haemocyte density and microbial load may be used as indicators of fungal pathogenicity in larvae of Galleria mellonella. Microbes Infect. 3, 1389-1395.

Bergin, D., Reeves, E., Renwick, J., Wientjes, Kananagh K., 2005. Superoxide production in Galleria mellonella hemocytes: identification of proteins homologous to the NADPH oxidase complex of human neutrophils. Infect. Immun. 73, 4161-4170.

Bharadwaj, L., Dhami, K., Schneberger, D., Stevens, M., Renaud, C., Ali, A., 2005. Altered gene expression in human hepatoma HepG2 cells exposed to low-level 2,4dichlorophenoxyacetic acid and potassium nitrate. Toxicol. in Vitro 19, 603-619.

Brennan, M., Thomas, D., Whiteway, M., Kavanagh, K., 2002. Correlation between virulence of Candida albicans mutants in mice and Galleria mellonella larvae. FEMS Immunol. Med. Microbiol. 34, 153-157.

Browne, N., Hackenberg, F. Streciwilk, W., Tacke, M., Kavanagh, K., 2014. Assessment of in vivo antimicrobial activity of the carbene silver (I) acetate derivative SBC3 using Galleria mellonella larvae. Biometals 27, 745-752.

Browne, N., Heelan, M., Kavanagh, K., 2013. An analysis of the structural and functional similarities of insect haemocytes and mammalian phagocytes. Virulence 4, 597-603. 
Browne, N., Surlis, C., Maher, A., Gallagher, C., Carolan, J., Clynes, M., Kavanagh, K., 2015. Prolonged pre-incubation reduces the immune response of Galleria mellonella larvae to bacterial and fungal infection. Virulence $6(6), 1-8$

Buyukguzel, E., Buyukguzel, K., Snela, M., Erdem, M., Radtke, K., Ziemnicki, K., Adamski, Z. 2013. Effect of boric acid on antioxidant enzyme activity, lipid peroxidation, and ultrastructure of midgut and fat body of Galleria mellonella. Cell Biol. Toxicol. 29, $117-129$.

Camargo, J., Alonso, A., Salamanca, A., 2005. Nitrate toxicity to aquatic animals: a review with new data for freshwater invertebrates. Chemosphere 58, 1255-1267.

Carmona, E.R., Escobar, B., Vales, G., Marcos, R., 2015. Genotoxic testing of titanium dioxide anatase nanoparticles using wing-spot test and the comet assay in Drosophila. Mutat. Res. 778, 12-21.

Chen, Z., Zhang, J., Stamler, J., 2002. Identification of the enzymatic mechanism of nitroglycerin bioactivation. PNAS 99, 8306-8311.

Clancy, R.M., Leszczynska-Piziak, J., Abramson, S.B., 1992. Nitric oxide, an endothelial cel relaxation factor, inhibits neutrophil superoxide anion production via a direct action on the NADPH oxidase. J. Clin. Invest. 90, 1116-1121.

Cook, S.M., McArthur, J.D., 2013. Developing Galleria mellonella as a model host for human pathogens. Virulence 4, 350-353.

Cotter, G., Doyle, S., Kananagh, K., 2000. Development of an insect model for the in vivo pathogenicity testing of yeasts. FEMS Immunol. Med. Microbiol. 27, 163-169.

Cox, J., Neuhauser, N., Michalski, A., Scheltema, R.A., Olsen, J.V., Mann, M., 2011. Andromeda: a peptide search engine integrated into the MaxQuant environment. J. Proteome Res. 10, 1794-1805

Debois, A.P., Coote, P.J., 2012. Utility of greater wax moth larva (Galleria mellonella) for the evaluating the toxicity and efficacy of antimicrobial agents. Adv. Appl. Microbiol. 78, $25-53$.

Deriagina, V.P., Mashkovtsev, luV, II'nitskii, A.P., 2003. Experimental study of the effect of sodium nitrate on the functional neutrophil and macrophage activity. Biomed. Khim. 49, 19-26.

Fallon, J., Kelly, J., Kavanagh, K., 2012. Galleria mellonella as a model for fungal pathogenicity testing. Methods Mol. Biol. 845, 469-485.

Fuchs, B., Mylonakis, E., 2006. Using non-mammalian hosts to study fungal virulence and host defense. Curr. Opin. Microbiol. 9, 346-351.

Grunwald, S., Adam, I.V., Gurmai, A.M., Bauer, L., Boll, B., Wenzel, U., 2014. The red flour beetle Tribolium castaneum as a model to monitor food safety and functionality. Adv. Biochem. Eng. Biotechnol. 135, 111-122.

Hord, N.G., 2011. Dietary nitrates, nitrites, and cardiovascular disease. Curr. Atheroscler. Rep. 13, 484-492.

Jander, G., Rahne, L.G., Ausbel, F.M., 2000. Positive correlation between virulence of Pseudomonas aeruginosa mutants in mice and insects. J. Bacteriol. 182, 3843-3845.

Kavanagh, K., Reeves, E.P., 2004. Exploiting the potential of insects for in vivo pathogenicity testing of microbial pathogens. FEMS Microbiol. Rev. 28, 101-112.

Lonberg, J.O., Weitzberg, E., Gladwin, M.T., 2008. The nitrate-nitrite-nitric oxide pathway in physiology and therapeutics. Nat. Rev. 7, 156-167.
Lundberg, J., Caristrom, M., Larsen, F., Weitzberg, 2011. Roles of dietary inorganic nitrate in cardiovascular health and disease. Cardiovasc. Res. 89, 525-532.

Maguire, R., Duggan, O., Kavanagh, K., 2016. Evaluation of Galleria mellonella larvae as an in vivo model for assessing the relative toxicity of food preservative agents. Cell Biol. Toxicol. 32, 209-216.

Moncada, S., Erusalimsky, J.D., 2002. Does nitric oxide modulate mitochondrial energy generation and apoptosis? Nat. Rev. 3, 214-220.

Mowlds, P. Barron, A., Kavanagh, K., 2008. Physical stress primes the immune response of Galleria mellonella larvae to infection by Candida albicans. Microbiol. Infect. 10, 628-634.

Mowlds, P., Kavanagh, K., 2008. Effect of pre-incubation temperature on susceptibility of Galleria mellonella larvae to infection by Candida albicans. Mycopathologia 165, 5-12.

Mukherjee, K., Altincicek, B., Hain, T., Domann, E., Vilcinskas, A., Chakraborty, T., 2010. Galleria mellonella as a model system for studying Listeria pathogenesis. Appl. Environ. Microbiol. 76, 310-317.

Munzel, T., Seyegh, H., Freeman, B.A., Taprey, M.M., Harrison, D.G., 1995. Evidence for enhanced vascular superoxide anion production in nitrate tolerance. J. Clin. Invest. 95, 187-194.

Romano, R., Zeng, C., 2007. Acute toxicity of sodium nitrate, potassium nitrate, and potassium chloride and their effects on the hemolymph composition and gill structure of early juvenile blue swimmer crabs (Portunus pelagicus Linnaeus) (Decapoda, Brachyura, Portunidae). Environ. Toxicol. Chem. 26, 1955-19.

Rowan, R., McCann, M., Kavanagh, K., 2009. Analysis of the response of Candida albicans cells to Silver(I). Med. Mycol. 47, 1-8.

Sarikaya, R., Cakir, S., 2005. Genotoxicity testing of four food preservatives and their combinations in the Drosophila wing spot test. Environ. Toxicol. Pharmacol. 20, 424-430.

Sebranek, J., Bacus, J., 2007. Cured meat products without direct addition of nitrate or nitrite: what are the issues? 53rd Intl Cong Meat Sci. Technol. 77, 136-147.

Soos, I., Szabad, J. 2014. Assaying benzene, a parquet varnish, and a synthetic thinner with respect to induction of in vivo chromosome loss in wing primordial cells of Drosophila. Mutat. Res. Genet. Toxicol. Environ. Mutagen. 763, 18-22.

Sydow, K., Daiber, A., Oelze, M., et al., 2004. Central role of mitochondrial aldehyde dehydrogenase and reactive oxygen species in nitroglycerin tolerance and cross-tolerance. J. Clin. Invest. 133, 482-489.

Tsai, C., Loh, J., Proft, T., 2016. Galleria mellonella infection models for the study of bacterial diseases and for antimicrobial drug testing. Virulence 7, 214-229.

Van Dijk, S., Lobsteyn, A.J., Weinsing, T., Breukink, H.J., 1983. Treatment of nitrate intoxication in a cow. Vet. Rec. 112, 272-274.

Vogel, H., Altincicek, B., Glöckner, G., Vilcinskas, A., 2011. A comprehensive transcriptome and immune-gene repertoire of the lepidopteran model host Galleria mellonella. BMC Genomics 2011 (12), 308

Wang, H., Huang, P., Tietao, L., Jian, L., Reinhold, J.H., Kui, L., et al., 2010. Reproductive toxicity of acrylamide-treated male rats. Reprod. Toxicol. 29, 225-230. 